\title{
PENGARUH MEDIA VISUAL (GAMBAR) TERHADAP KEMAMPUAN KOSAKATA ANAK AUTIS
}

\author{
Amalia Risqi Puspitaningtyas ${ }^{1}$ dan Vidya Pratiwi ${ }^{1}$ \\ ${ }^{1}$ Prodi Pendidikan Guru Sekolah Dasar, FKIP Universitas Abdurachman Saleh Situbondo \\ amaliarisqipuspitaningtyas@gmail.com
}

Naskah diterima: 3 Maret, 2020, direvisi: 20 Maret, 2020, diterbitkan: 31 Maret, 2020

\begin{abstract}
Barriers possessed by autistic children are communication and language, so that the vocabulary they have is limited. The purpose of this study is to describe the vocabulary skills of autistic children both before and after the intervention state and analyze visual media (pictures) of the vocabulary abilities of autistic children. This research method is quantitative using Single Subject Research (SSR) A-B$A$ design with $A$ is the baseline and $B$ is an intervention. The vocabulary of autistic children before intervention or on the implementation of $A-1$ is $24 \%$, which means that the vocabulary of autistic children is very low in recognizing the vocabulary of animals, fruits and objects, then the implementation of interventions $(B)$ the ability of autistic children rises to $60 \%$. Then the final implementation is the A-2 test stage as a benchmark for the subject without any intervention, and it turns out the subject's vocabulary ability increased to $75 \%$. Thus it can be concluded that the results of the study show that there is an influence of visual media (pictures) on the vocabulary of autistic children
\end{abstract}

Keywords: Autism, Visual Media (pictures), Vocabulary ability

\begin{abstract}
ABSTRAK
Hambatan yang dimiliki oleh anak autis yaitu komunikasidan bahasa, sehingga kosakata yang dimilikinya terbatas. Tujuan penelitian ini untuk mendeskripsikan kemampuan kosakata anak autis baik sebelum maupun setelah keadaan intervensi dan menganalisis media visual(gambar) terhadap kemampuan kosakata anak autis. Metode penelitian ini kuantitatif dengan menggunakan Single Subject Research (SSR) desain A-B-A dengan A adalah baseline dan B adalah intervensi. Kemampuan kosakata anak autis sebelum intervensi atau pada pelaksanaan A-1 sebesar 24\% yang berarti kemampuan kosakata anak autis sangat rendah dalam mengenal kosakata hewan,buah-buahan dan benda,selanjutnya pelaksanaan intervensi (B)kemampuan anak autis naik menjadi $60 \%$. Kemudian pelaksanaan terakhir yaitu tes tahap A-2 sebagai tolak ukur subjek tanpa adanya intervensi, dan ternyata kemampuan kosakata subjek meningkat menjadi $75 \%$. Dengan demikian dapat disimpulkan hasil penelitian menunjukkan ada pengar uhmedia visual (gambar) terhadap kemampuan kosa kata anak autis.
\end{abstract}

Kata Kunci: Autis, Media Visual (gambar), Kemampuan kosakata

\section{PENDAHULUAN}

Proses pembelajaran merupakan kegiatan belajar mengajar yang menimbulkan adanya interaksi antara siswa dengan guru. Anak autis merupakan salah satu dari anak berkebutuhan khusus. Anak autis akan sangat terlihat sangat sensitif atau bahkan tidak responsif terhadap stimulus dari panca indera. Anak autis beragam macamnya baik dalam kemampuan yang dimiliki, tingkat intelegensi bahkan perilakunya. Karakter anak autis terdapat dua jenis yaitu bersifat agresif dan bersifat pasif. Jika anak autis berada salam satu ruangan dengan orang lain anak autis akan menyibukkan diri dengan aktivitas yang melibatkan diri sendirinya yang pada umumnya dengan benda mati, kalaupun di suruh berkumpul dengan yang lainnya anak 
autis akan mengalami kesulitan untuk interaksi dan berkomunikasi. Anak autis mengalami keterbatasan bahasa.

Dalam proses pembelajaran, pendamping guru bagi anak autis harus memiliki kepekaan dalam kegiatan pembelajaran, karena anak autis mengalami gangguan yang kompleks yang menyangkut komunikasi sehingga dalam proses pembelajaran anak autis tidak mudah memahami dan mengerti apa yang di paparkan oleh guru. Modal seseorang untuk memperoleh informasi melalui lingkungan yaitu dari interaksi dan komunikasi. Dalam hal ini jika seorang siswa mengalami hambatan dalam interaksi dan komunikasi akan mengalami hambatan dalam kegiatan belajarnya. Pembelajaran bahasa memiliki empat aspek yang dipelajari dan saling berkaitan. Keempat aspek bahasa tersebut adalah ketrampilan menyimak atau mendengarkan, ketrampilan berbicara, ketrampilan membaca dan ketrampilan menulis. Dari keempat aspek tersebut di atas, yang paling sering digunakan seteelah mendengarkan adalah ketrampilan berbicara.

Bahasa juga sebagai salah satu alat komunikasi terpenting dalam berinteraksi. Dalam menguasai kemampuan berbahasa tidak lepas dari penguasaan kosakata. Penguasaan kosakata yang memadai akan memperlancar siswa dalam berkomunikasi, mempermudah siswa untuk memahami bahasa yang terdapat dalam buku-buku pelajaran hal ini sejalan dengan pendapat Sturtevant (dalamYonohudiyono,2007:3).Penguasaan kosakata merupakan hal yang sangat penting dalam mencapai penguasaan bahasa, semakin banyak kosakata yang dimiliki seseorang maka semakin banyak pula ide dan gagasan yang dikuasai seseorang. Penguasaan kosakata merupakan ukuran pemahaman seseorang terhadap kosakata suatu bahasa dan kemampuannya menggunakan kosakata tersebut baik secara lisan maupun tertulis (Aris Yunisah, 2007:11). Penguasaan kosakata merupakan bagian dari penguasaan bahasa karena jika seseorang menguasai bahasa berarti orang tersebut menguasai kosakata.

Tanggungjawab guru dalam proses pembelajaran sangat penting yaitu merancang dan melaksanakan pembelajaran sesuai dengan tujuan yang telah di tetapkan.Bahasa verbal merupakan hal wajib yang harus dimiliki guru dalam proses pembelajaran, sehingga pembelajaran tersebut tersampaikan kepada siswa. Akan tetapi pembelajaran hanya menggunakan bahasa verbal saja akan menimbulkan persoalan bagi peserta didik,terutama bagi anak yang berkebutuhan khusus seperti anak autis. Hal ini sesuai dengan hasil pengamatan pada bulan maret- juni 2019 di SDN 8 Kilensari didapat anak autis yang mengalami gangguan dalam berbahasa dan kemampuan kognitifnya masih rendah. Setiap diajak berkomunikasi anak autis tersebut selalu menirukan ucapan orang lain dan tidak ada kontak mata. Jika kita ingin mengajak berkomunikasi kita harus menyentuh bahu dan memfokuskan pandangan anak tersebut.

Ketika guru menyampaikan suatu materi pelajaran anak tersebut mengalami kesulitan untuk berpikir sehingga perlu alat bantu secara nyata yang dapat memudahkan anak menjadi mengerti isi materi yang disampaikan oleh guru. Dalam hal ini guru harus memiliki strategi, pendekatan metode atau media dalam memberikan pembelajaran terutama bagi anak autis.Dalam proses pembalajaran guru harus merancang perangkat pembelajaran secara baik, salah satunya dalam pembelajaran kosakata.Para guru dituntut agar mampu menggunakan media pembelajaran yang telah disediakan disekolah dalam upaya untuk mencapai pembelajaran yang diharapkan (Arsyad,2010:2).Dalam proses pembelajaran terdapat beberapa komponen yang saling berkaitan satu dengan yang lainnya untuk mencapai suatu tujuan pembelajaran salah satunya yaitu media.Peran media pembelajaran merupakan hal yang terpenting dalam penyampaian materi. 
Media adalah segala bentuk dan saluran yang digunakan untuk menyampaikan pesan atau informasi (AECT,1977 dalam Arsyad, 2010:3).Media merupakan pendukung dalam proses belajar dan dapat mempermudah guru untuk menyampaikan materi. Berbagai jenis media yang dapat digunakaan dalam proses belajar bagi anak autis, salah satunya yaitu media visual.Untuk memperlancar pemahaman dan memperkuat ingatan anak autis bisa menggunakan media visual, media visual tersebut dapat berupa gambar benda yang mirip dengan benda aslinya. Media visual merupakan salah satu cara yang digunakan untuk meningkatkan kemamapuan kosakata jika siswa berinteraksi langsung dengan visual (image) sehingga terjadinya proses informasi. Penggunaan media visual dalam pembelajaran akan efektif jika pemahaman guru terhadap karakteristik dari media yang akan digunakan, sehingga perlu adanya tindak lanjut dalam penggunakan media visual yang digunakan untuk pembelajaran anak autis.

Dari pemaparan di atas maka perlu dilakukan penelitian yang berkaitan dengan media pembelajaran tersebut dengan judul "Pengaruh Media Visual (gambar) terhadap kemampuan kosakata anak autis".

\section{METODOLOGI}

Penelitian tentang media visual(gambar) untuk meningkatkan kemampuan kosakata anak autis menggunakan metode penelitian eksperimen dengan jenis single subject research (SSR) dengan menggunakan pendekatan kuantitatif, Cresswell (2009: 159).Penggunaan metode ini disesuaikan dengan kebutuhan subjek, peneliti yang ingin mengetahui pengaruh dari tindakan terhadap tingkah laku apakah tindakan tersebut berpengaruh atau tidak. Sampel penelitian ini yaitu anak autis yang ada di SDN 8 Kilensari Kecamatan Panarukan Kabupaten Situbondo.

Desain yang digunakan dalam penelitian ini adalah desain A1-B-A2 yang artinya desain ini memberikan suatu hubungan sebab akibat yang lebih kuat diantara variabelnya. Pada tahap A-1 merupakan tahap tes awal kemampuan subjek menyebutkan kosakata sebelum pemberian treatmen dengan menggunakan media visual (gambar), pelaksaanaan ini dilakukan selama 5 sesi. Tahap B yaitu intervensi atau pemberian treatmen. Pelaksanaan pada tahap ini dengan diberikan treatmen berupa media visual(gambar) untuk meningkatkan kemampuan kosakata, pada tahap ini dilaksanakan selama 7 kali sesi. Tahap terakhir yaitu A2 yang merupakan tahap pengulangan A-1 yang dimaksud sebagai evaluasi dari pengaruh pemberian treatment dalam kemampuan kosakata dengan dilaksanakan selama 5 sesi.

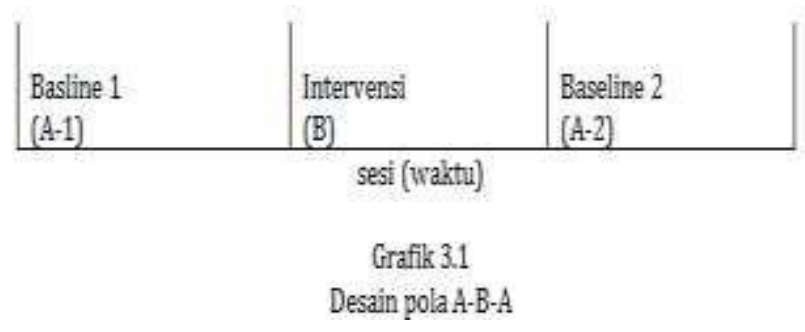

Gambar 1. Desain Pola A-B-A

Keterangan:

A-1 (Baseline 1): Kondisi awal pada saat subjek belum di lakukan intervensi yakni kemampuan mengenal kosakata subjek sebelum diberikan media berupa visual (gambar). 
B (treatmen) : kondisi kemampuan subjek dalam kemampuan mengenal kosakata selama treatmen. Pada tahap ini subjek diberi treatmen berupa media visual (gambar) yang dilakukan dengan waktu 60 menit setiap pertemuan.

A-2 (Baseline-2): Pengulangan dari pelaksanaan A-1 dengan mengevaluasi kembali perkembangan kemampuan mengenal kosakata setelah diberikan treatmen berupa media visual (gambar).

Analisis data yang dipakai dalam penelitian ini adalah analisis dalam kondisi dan analisis antar kondisi. Analisis perubahan dalam kondisi adalah perubahan data dalam suatu kondisi pelaksanan A-1 atau intervensi (B). Adapun komponen yang akan dianalisis dalam kondisi ini meliputi panjang kondisi, kecenderungan arah, tingkat stabilitas, tingkat perubahan, jejak data dan rentang. Sedangkan analisis antarkondisi terkait komponen jumlah variabel yang dirubah, perubahan kecenderungan dan efeknya, perubahan stabilitas, perubahan level dan data tumpang tindih (overlap).

Teknik pengumpulan data yang digunakan dalam penelitian ini adalah observasi, tes, wawancara dan dokumentasi. 1). Teknik observasi yaitu pengumpulan data yang dilakukan degan cara mengamati secara sistematik dan digunakan untuk memantau proses pembelajaran yang dilakukan. 2). Teknik tes yaitu kemampuan hasil belajar dengan mengukur pencapaian kemampuan kosakata sebelum dan sesudah diberikan perlakuan. Tes hasil belajar diperoleh dari melihat hasil berdasarkan asepek kemampuan siswa dalam mengenal kosakata. 3). Teknik wawancara yaitu untuk mengetahui kemampuan subjek dan mewancarai narasumber yaitu guru pendamping. Wawancara yang dilakukan terhadap guru untuk menggali informasi terkait keadaan subjek. 4) Teknik dokumentasi yaitu menjadi pelengkap saat akan menganalisis data. Teknik ini digunkan sebagai pendukung data hasil observasi.

\section{HASIL DAN DISKUSI}

Pengambilan data disusun dengan hasil desain A1-B-A2 terkait kemampuan kosa kata anak autis. Pelaksanaan awal dengan melakukan pengumpulan data untuk mengukur subjek dalam kemampuan kosa kata dengan menyebutkan kata yang difokuskan pada kosakata hewan dan tumbuhan. Pengumpulan data A-1dilakukan oleh peneliti dengan persetujuan wali kelas. Pada pelaksanaan awal ini dilakukan selama 5 sesi, kemudian langkah selajutnya adalah melakukan intervensi dengan memberikan perlakuan terhadap subjek. Ada tidaknya pengaruh media visual terhadap kemampuan kosa kata dapat diketahui dari hasil perbandingan antara kondisi A-1 dengan intervensi (B). Pelaksanaan intervensi yaitu subjek diberikan perlakukan berupa media visual yang berupa kosa kata hewan,tumbuhan dan kata benda.Dalam pengumpulan data pelaksanaan intervensi (B) dilaksanakan selama 7 sesi,kemudian setelalah pelaksnaan intervensi akan dilanjutkan dengan pelaksanaan A-2 sebagai tahapan kontrol. Pelaksanaan A-2 dilakukan selama 5 sesi. Untuk mengetahui serta memperjelas perkembangan dari seluruh hasil penelitian ini, pada pelaksanaan A1, intervensi dan A-2, dapat disajikan dalam tabel dan grafik berikut ini. 
Tabel 1. Hasil Skor kemampuan kosakata anak autis

\begin{tabular}{|c|c|c|}
\hline Kondisi & Sesi & Data Hasil \\
\hline \multirow[t]{5}{*}{ BaseLine 1 (Al) } & 1. & $22 \%$ \\
\hline & 2. & $24 \%$ \\
\hline & 3. & $26 \%$ \\
\hline & 4. & $24 \%$ \\
\hline & 5 & $28 \%$ \\
\hline \multirow[t]{7}{*}{ Intervensi } & 1. & $32 \%$ \\
\hline & 2. & $36 \%$ \\
\hline & 3. & $40 \%$ \\
\hline & 4. & $45 \%$ \\
\hline & 5. & $49 \%$ \\
\hline & 6. & $54 \%$ \\
\hline & 7. & $60 \%$ \\
\hline \multirow[t]{5}{*}{ BaseLine 2 (A2) } & 1. & $65 \%$ \\
\hline & 2. & $68 \%$ \\
\hline & 3. & $70 \%$ \\
\hline & 4. & $72 \%$ \\
\hline & 5. & $75 \%$ \\
\hline
\end{tabular}

Berdasarkan data diatas, selanjutnya dapat disajikan dalam bentuk grafik sebagai berikut :

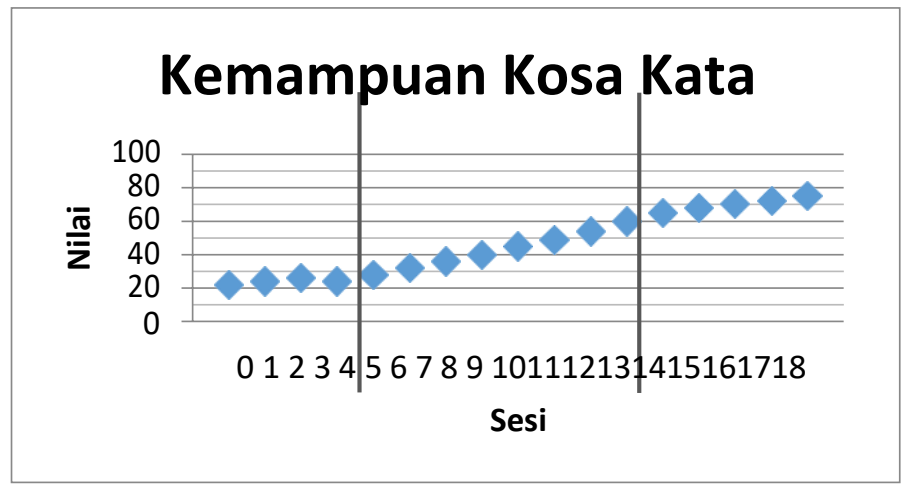

Gambar 2. Kemampuan Kosakata Anak Autis Tahap A1, Tahap B dan Tahap A2

Tabel dan grafik di atas merupakan hasil akumulasi skor kemampuan menyebutkan kosakata yang telah dicapai oleh subjek. Pada setiap pelaksanaan dari A-1, Intervensi, A-2 menunjukkan bahwa media visual (gambar) berpengaruh terhadap kosa kata anak autis dengan melihat skor akhir. Skor akhir dari masing2 pelaksanaan menunjukkan peningkatan yang signifikan yaitu dari dengan skor $28 \%$ kemudian Intervensi sebesar $60 \%$ dan pelaksanaan terakhir yaitu $75 \%$. Skor tersebut menunjukkan bahwa pelaksanaan A-2lebih tinggi dibandingkan denganA-1, jadi media visual (gambar) berpengaruh terhadap kemampuan kosakata anak autis.

\section{Analisis Dalam Kondisi}

Analisis dalam kondisi memperhatikan komponen- komponen yang akan dianalisis diantaranya meliputi panjang kondisi, estimasi kecenderungan arah, kecenderungan stabilitas data dan rentang, serta perubaha level. Diketahui bahwa panjang kondisi pelaksanaan $A-1=5$, intervensi $(B)=7$ dan $A-2=5$. Hasil kecenderungan arah selama pelaksanaan A-1 sejajar, akan tetapi pelaksanaan intervensi (B) meningkat hingga pelaksanaan A-2. Untuk kecenderungan stabilitas pada pelaksanaan A-1= stabil, intervensi $(B)=$ stabil dan A-2 = stabil. Level perubahan pada pelaksanaan A-1= +4 , Intervensi $(B)=$ +24 dan pelaksanaan A-2 $=+7$. Adapun hasil analisis visual dalam kondisi tersaji pada tabel 2 sebagai berikut: 


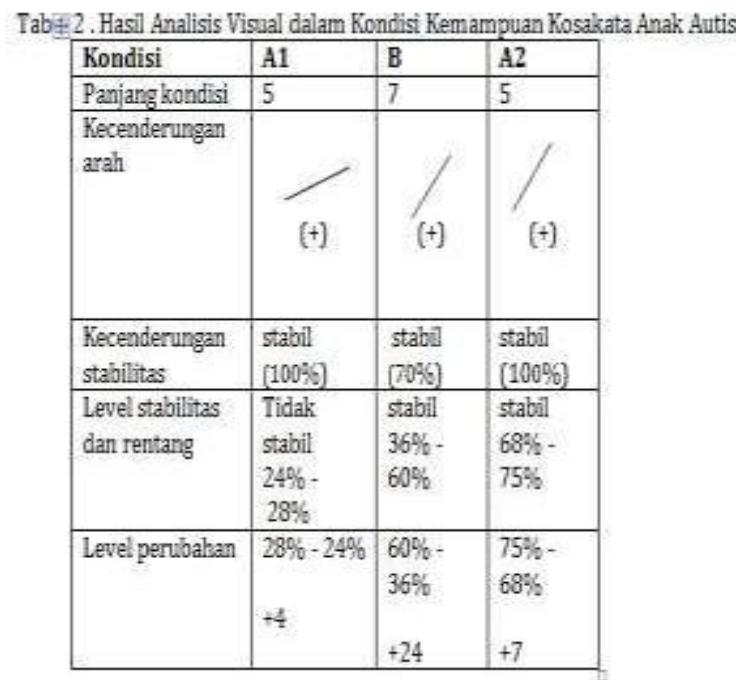

\section{Analisis Antar Kondisi}

Analisis antar kondisi dilakukan setelah data yang diperoleh menunjukkan kestabilan.Penggunaan data yang bervariasi (tidak stabil/ variabel) akan mempersulit interpretasi data. Faktor- faktor yang dianalisis pada analisis antar kondisi yaitu jumlah variabel yang dirubah,perubahan arah dan efeknya, perubahan stabilitas, level perubahan dan presentase overlap. Berdasrkan hasil analisis data dapat disimpulkan bahwa pelaksanaan media visual (gambar) berpengaruh dalam meningkatkan kemampuan kosakata.

Hasil data antara A-1 dengan B tidak terdapat data yang overlap, data ini menunjukkan bahwa media visual (gambar) berpengaruh dalam meningkatkan kosakata. Data anatara B dengan A-2 tidak terdapat overlap, sehingga menunjukkan hasil yang baik. Dengan kata lain hasil keseluruhan pelaksanaan media visual (gambar) disimpulkan berpengaruh dalam kemampuan kosakata, karena adanya perubahan data yang semakin baik yaitu pada pelaksanaan A-2 yang diperoleh data lebih tinggi dibandingkan pelaksanaan A-1. Darihasil data tersebut pemberian intervensi (B) berpengaruh terhadap kemampuan kosakata.

Tabel 3. Hasil Analisis Data antar Kondisi kemampuan kosakata anak autis

\begin{tabular}{|l|l|c|}
\hline \multicolumn{1}{|c|}{ Kondisi } & B/A1 & A2/B \\
\hline Jumlah variable yang diubah & 1 & 1 \\
\hline Kecenderungan dan efeknya & & $(+)(+)$ \\
\hline Perubahan stabilitas & $(+)(+)$ & Stabil ke stabil \\
\hline
\end{tabular}




\begin{tabular}{|l|l|l|}
\hline $\begin{array}{l}\text { Perubahan } \\
\text { level }\end{array}$ & $\begin{array}{c}28 \%-60 \% \\
+38\end{array}$ & +10 \\
\hline Presentase overlap & $0: 7 \times 100$ & - \\
& $=0 \%$ & \\
\hline
\end{tabular}

Komponen yang akan dianalisis anatar kondisi meliputi jumlah variabel yang akan diubah, kecenderungan dan efeknya, perubahan stabilitas, perubahan level dan presentase data yang tumpang tindih (overlap). Berdasarkan hasil penelitian ini menunjukkan bahwa pemberian intervensi berupa media visual (gambar) berpengaruh terhadap kemampuan kosakata anak autis.

\section{Pembahasan Hasil Penelitian}

Pada penelitian ini bertujuan untuk meningkatkan kemampuan kosakata anak melalui media visual (gambar). Dari hasil penelitian tersebut dapat diuraikan bahwa media visual (gambar) dapat memperlancar pemahaman dan memperkuat ingatan. Visual dapat pula menumbuhkan minat belajar anak, agar menjadi efektif sebaiknya visual diletakkan pada situasi yang berarti sehingga anak dapat berinteraksi dengan visual (image) untuk terjadinya proses informasi.

Kosakata membentuk aspek dalam bahasa yang perlu dipelajari oleh anak termasuk anak autis. Kemampuan berkomunikasi anak autis mengalami keterbatasan. Dengan mempelajari kosakata keterampilan anak dalam berbahasa juga meningkat. Pentingnya belajar kosakata menurut Tarigan (2011:2) bahwa dengan "kosakata anak dapat terampil dalam berbahasa dan dengan banyaknya kosakata dapat meningkatkan kuantitas dan kualitas belajar anak dalam berbagai bidang studi yang mereka peroleh di sekolah".

Kondisi subjek dilapangan bahwa subjek mengalami keterbatasan dalam berkomunikasi. Setiap diajak berkomunikasi subjek selalu sibuk dengan dunianya sendiri, sehingga orang lain yang ingin mengajak berkomunikasi harus menepuk pundaknya agar subjek bisa fokus. Ketika guru menjelaskan materi subjek mengalami hambatan dalam penerimaan materi, sehingga subjek memerlukan media yang sesuai dengan kebutuhannya yaitu media visual. Media visual yang sesuai dengan kebutuhan subjek yaitu media visual (gambar). Media visual sangat berpengaruh terhadap perbendaharaan kata, daya ingat dan kemampuan subjek dalam menyebutkan kosakata sehingga subjek tidak mengalami ketertinggalan dalam kemampuan berbahasa. Pelaksanaan A-1 dilakukan selama 5 sesi. Hasil menunjukkan arah yang rata sesuai dengan kemampuan awal subjek.Pernyataan di atas dapat dibuktikan dengan adanya peningkatan di masing- masing pelaksanaan yaitu dimulai pada A-1 diperoleh hasil 28\% bahwa belum adanya perubahan karena subjek hanyadisuruh untuk menyebutkan nama hewan, buah dan kata benda tanpa adanya intervensi. Pada pelaksanaan intervensi (B)mengalami pengingkatan yang signifikan yaitu dengan hasil $60 \%$ dibandingkan pada A-1 yang dilakukan selama 7 sesi. Faktor yang mempengaruhi peningkatan pada pelaksanaan ini yaitu adanya treatmen berupa media visual (gambar).

Pelaksanaan kedua yaitu intervensi (B) media visual (gambar) efektif terhadap kemampuan kosakata subjek karena subjek lebih tertarik melakukan pembelajaran karena menggunakan media berupa gambar. Pelaksanaan terakhir yaitu A-2 yang nenunjukkan peningkatan di bandingkan pada A-1 (sebelum intervensi) dengan hasil $75 \%$ yang dilakukan selama 5 sesi. Adapun beberapa faktor yang mempengaruhi terjadinya perubahan yang lebih 
baik yaitu media pembelajaran yang menunjang dan motivasi dari lingkungan untuk subjek dalam melaksanakan proses pembelajaran.

Berdasarkan hasil analisis data dan pembahasan diatas, membuktikan pemberian intervensi media visual (gambar) sangat efektif terhadap kemampuan mengenal kosakata. Dalam keterampilan berbahasa seseorang dapat berupa yaitu mendengar, berbicara, membaca dan menulis. Dalam penelitian ini tidak terlepas dari beberapa kendala dalam pelaksanaan penelitian, ada beberapa faktor yang menjadi penyebabnya yaitu: kondisi dari siswa yang lainya ketika pelaksanaan A-1 maupun intervensi (B) sehingga konsentrasi subjek terganggu. Kondisi subjek yang mengalami ketidakstabilan emosi membuat peneliti harus menunggu mood subjek baik.

\section{KESIMPULAN}

Berdasarkan hasil penelitian dapat disimpulkan bahwa :

1. Pelaksanaan pembelajaran dengan menggunakan media visual (gambar) berpengaruh terhadap kemampuan kosakata anak autis dengan baik karena subjek bisa menyebutkan kosakata dengan benar.

2. Kemampuan kosakata anak autis sebelum intervensi atau pada pelaksanaan A-1 sebesar 24\% yang berarti kemampuan kosakata anak autis sangat rendah dalam mengenal kosakata hewan,buah-buahan dan benda,selanjutnya pelaksanaan intervensi (B)kemampuan anak autis naik menjadi $60 \%$. Kemudian pelaksanaan terakhir yaitu tes tahap A-2 sebagai tolak ukur subjek tanpa adanya intervensi, dan ternyata kemampuan kosakata subjek meningkat menjadi $75 \%$.

3. Media visual (gambar) berpengaruh terhadap kemampuan kosa kata anak autis dari tahap A-1 ke intervensi (B) sebesar 22\% ke 60\% tingkat peningkatan sebesar $38 \%$. Dapat disimpulkan bahwa media visual (gambar) berpengaruh terhadap peningkatkan kemampuankosakata anak autis.

\section{ACKNOWLEDGMENT}

Peneliti ucapkan terima kasih yang sedalam-dalamnya kepada DRPM Kemenristek Dikti, Rektor UNARS Situbondo beserta lainnya yang ikut dalam kontribusi dalam penelitian ini, LP3M UNARS Situbondo dan seluruh Dewan Guru SDN 8 Kilensari Kecamatan Panarukan Situbondo-Indonesia yang telah bersedia bekerja sama dan mengijinkan peneliti melaksanakan penelitian.

\section{BIBLIOGRAPHY}

Arsyad, Azhar. 2010. Media Pembelajaran. Jakarta: Rajawali Pers.

Creswell, W.J. 2009. Reseach Design PendekatanKualitatif Kuantitatif, dan Mixed.

TerjemahanFawaid. 2010. Yogyakarta: PustakaPelajar.

Irwanto, Setiadi, Rudy, dkk. 2011. Austime Dari A Sampai Z: EdisiKhususMajalahAnakSpesial. Jakarta: CV. AnakSpesial Mandiri.

Noviani, Elisa. 2014. Pengaruh Permainan Kartu Bergambar Untuk Meningkatkan Kosa Kata Anak Autis Kelas TK di Sekolah Khusus Bina Anggita Yogyakarta. Jurnal Pendidikan Khusus Edisi Januari Tahun 2014

Sunarto, J, dkk. 2005. PengantarPenelitiandenganSubyek Tunggal. Tsukuba: Universitas Tsukuba

Santrock, W. John. 1995. Life-Span Developmental: Perkembangan Masa Hidup. Jakarta: Erlangga. 
Soetjiningsih\&Ranuh, IG.N Gede. 1995. Tumbuh Kembang Anak. Jakarta: PenerbitBukuKedokteran EGC.

Tarigan, Henry Guntur. 2011. Pengajaran Kosa Kata. Bandung: Angkasa 